\title{
Polyphenolic contents and antimicrobial activity of different extracts of Padina boryana Thivy and Enteromorpha sp marine algae
}

\author{
Manal Y. Sameeh ${ }^{1}$, Amal A. Mohamed ${ }^{2}$, Ahmed M Elazzazy ${ }^{3 *}$ \\ ${ }^{1}$ Chemistry Dept., University College - Al Leith- Umm Al-Qura University, Saudí Arabia. ${ }^{2}$ Plant Biochemistry Dept., National Research Centre, 33 El \\ Bohouth St., Dokki, Giza, Egypt. ${ }^{3}$ Department of Chemistry of Natural and Microbial Products, Division of Pharmaceutical and Drug Industries, National \\ Research Centre, Dokki, Giza, Egypt.
}

\section{ARTICLE INFO \\ Article history: \\ Received on: 03/04/2016 \\ Revised on: 05/05/2016 \\ Accepted on: 30/06/2016 \\ Available online: 26/09/2016}

Key words:

Antimicrobial activity,

ethanolic extract, flavonoid,

marine algae, phenolic.

\begin{abstract}
Marine algae are potential sources of biologically active compounds with antiviral, antimicrobial and anticancer activities. Two species of marine algae, Padina boryana Thivy and Enteromorpha sp were collected from the Red Sea. Both species were extracted with ethanol, acetone, and hexane. The extracts of each sample were examined for, total phenolic, total flavonoid contents and antimicrobial activities. The results showed that solvents with different polarities have various effects on phenolic and flavonoid contents. Among the tested solvents, ethanolic extract of Padina boryana Thivy and Enteromorpha sp showed the highest phenolic content. Results also indicated that the extracts of Padina boryana Thivy showed higher antimicrobial activity compared to Enteromorpha $s p$. The present study demonstrates that both algae species exhibited excellent antimicrobial properties which may use as natural food preservative for possible application in food for health promotion.
\end{abstract}

\section{INTRODUCTION}

The marine environment is a good source of bioactive secondary metaboliets, many of which exhibit structural features not found in terrestrial natural products (Cantillo et al., 2010). Marine seaweeds contains many valuable components that could potentially be exploited as functional ingredients and therapeutic agents. (Guptaand Abu-Ghannam, 2011). Recently, researchers have described a wide range of biological activities for algal compounds including antibiotic, anti-inflammatory, anti- fungal anticancer, and antineoplastic (Ayyad et al., 2003; Lincolon et al., 1991). Seaweeds are of nutritional interest as they are low calorie food and are rich in vitamins, antioxidant enzymes, proteins, polyphenolic compounds, sulphated polysaccharides and dietary fibers (Burtin 2003; MacArtain et al., 2007). Several in vitro studies have demonstrated that algal derived some

\footnotetext{
* Corresponding Author

Ahmed M Elazzazy, Department of Chemistry of Natural and Microbial Products, Division of Pharmaceutical and Drug Industries, National Research Centre, Dokki, Giza, Egypt.Email: ahmedazazy8@hotmail.com
}

phytochemicals such as polyphenols and flavonoids showed antioxidant and antimicrobial activity (Chandini et al., 2008; Zaragoza et al., 2008; Abd El-Aty et al., 2014). Phenolic compounds are diverse plant secondary metabolites comprised of aromatic rings, phenolic compounds from medicinal herbs and dietary plants include phenolic acids, flavonoids, tannins, stilbenes, coumarins, lignans, quinones, and others. Traditionally, many substances obtained from seaweeds are considered as a source of bioactive compounds which they have been used for decades in medicine and pharmacotherapy, whereas some of the isolated substances have bacteriostatic and bactericidal properties (Nair et al., 2007; O’Sullivan 2010).

The extracts and active constituents of various marine algae have been shown to antimicrobial potential (Lima-Filho et al., 2002; Paul et al., 2006). The antimicrobial compounds derived from the marine algae consist of a diverse group of chemical compounds (Nor Afifah et al., 2010). The ability of algae to produce antimicrobial substances could be used not only as a defense agent (against pathogens) but also as pharmaceutical bioactive natural compounds. 
Though much is known about the chemistry and the antimicrobial action of several phytochemicals, very few reports are available on the possible mechanism of action. Algal antimicrobial activity has been recognized based on existence of compounds belonging to numerous chemical classes including phenols, fatty acids, indoles, terpenes. Each of the various types of antibiotics kill microorganisms in a unique way. Some disturb the structure of the bacterial cell wall; others interfere with the production of essential proteins; and still others interfere with the transformation (metabolism) of nucleic acid (Flodin, and Whitfield 2000; Jin et al., 2006). The aim of this study is to evaluate the antimicrobial activity of ethanol, acetone, and hexane extracts of Padina boryana Thivy and Enteromorpha sp. Besides, phenolic and flavonoid content were determined as well.

\section{MATERIALS AND METHODS}

\section{Chemicals}

Folin-ciocalteu reagent, gallic acid and ethanol were purchased from Merck Company (Darmstadt, Germany). All other chemicals and reagents such as aluminum chloride and sodium hydroxide were obtained from BDH, Dorset, UK. The HPLC grade organic solvents were obtained from Merck. All other chemicals were of analytical-grade purity

\section{Algae collection and extraction}

Two marine algae were collected by hand picking from the Red Sea in Al-Leith Provence, Saudia during June 2015 (Fig. 1). Algal samples were cleaned from epiphytes, extraneous matter and necrotic were removed. Samples were washed thoroughly, air dried, cut into fine pieces and then ground in a tissue grinder until reach fine powder shape.
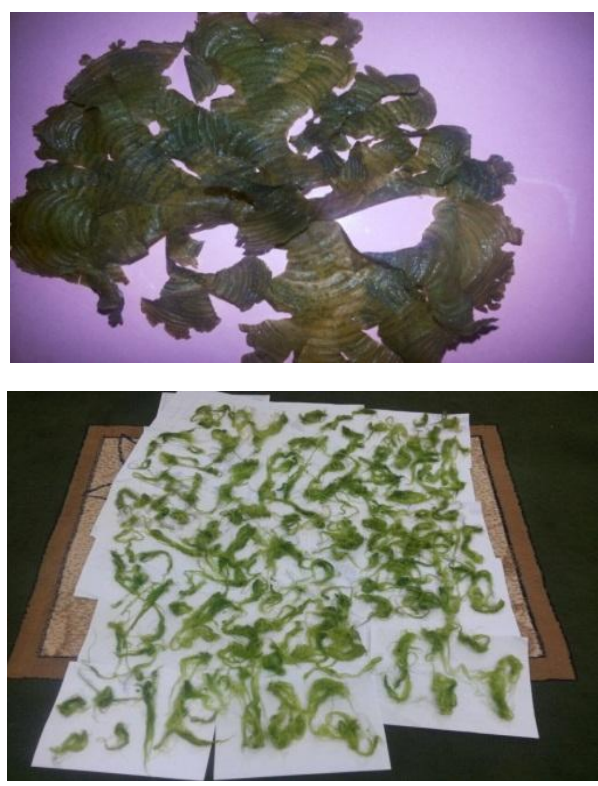

Fig. 1: (A). Padina boryana Thivy and (B). Enteromorpha sp

The pulverized algal material (10 g) was macerated separately with $(200 \mathrm{ml})$ of ethanol, acetone, and hexane at room temperature for $48 \mathrm{~h}$. After filtration through Whatman No.4 filter paper, algae residue was re-extracted twice with the same solvents. The pooled extracts were concentrated to remove the solvents completely from the extract. The dry crude extract was redissolved in $5 \mathrm{ml}$ using the same solvents (Abd El -Aty et al., 2014).

\section{Estimation of total phenolic content}

Total phenolic (TP) contents were determined by the spectrophotometric method (Slinkard and Singleton, 1977). In brief, a $0.5 \mathrm{ml}$ of each extract was made up to $3 \mathrm{ml}$ with distilled water, and then mixed with $0.5 \mathrm{ml}$ of Folin-Ciocalteu's phenol reagent. After $5 \mathrm{~min}, 2 \mathrm{ml}$ of a $2 \% \mathrm{Na}_{2} \mathrm{CO}_{3}$ solution were added to the mixture and thoroughly mixed. The mixture was kept at $30{ }^{\circ} \mathrm{C}$ for $60 \mathrm{~min}$ in dark place, and then the absorbance was recorded at $650 \mathrm{~nm}$. The measurement was compared to a standard curve prepared with gallic acid solution. The total phenolic content was expressed as milligrams of gallic acid equivalents per gram of dried weight.

\section{Determination of total flavonoid content}

Total flavonoid (TF) was determined by a colorimetric method as described by Zhishen et al., (1999). A $0.5 \mathrm{ml}$ of each extract was made up to $1 \mathrm{ml}$ with methanol. Afterwards $0.4 \mathrm{ml}$ of distilled water was added followed by $0.3 \mathrm{ml}$ of $5 \% \mathrm{NaNO}_{2}$ solution and the mixture was left for $5 \mathrm{~min}$.

Thereafter, $0.3 \mathrm{ml}$ of $(10 \%) \mathrm{AlCl}_{3}$ solution was added and allowed to stand for $6 \mathrm{~min}$. Two $\mathrm{ml}$ of $(1 \mathrm{M}) \mathrm{NaOH}$ solution was added to the mixture and the final volume was adjusted to 10 $\mathrm{ml}$ with distilled water. The mixture was thoroughly shaken and allowed to stand for $15 \mathrm{~min}$. Absorbance of the reaction mixture was read at $510 \mathrm{~nm}$. The concentrations of total flavonoids were determined as quercetin equivalents $(\mathrm{mg} / \mathrm{g}$ of dry weight).

\section{Antimicrobial activity}

\section{Microbial strains}

The algal extracts were tested for their antimicrobial activity against seven Gram-negative strains (i.e. Escherichia coli ATCC 11229, Moraxella catarrhalis ATCC 25238, Klebsiella oxytoca ATCC 49131, Klebsiella pneumoniae ATCC 700603, Neisseria gonorrhoeae ATCC 49226, Salmonella typhimurium ATCC 14028, Serratia sp. ATCC 39006 and five Gram positive strains (i.e. Methicillin-resistant Staphylococcus aureus (MRSA) ATCC 43330, Micrococcus luteus ATCC 49732, Staphylococcus epidermidis ATCC 12228 Enterococcus faecalis ATCC 29212, Staphylococcus aureus ATCC 25923 and a pathogen fungus (i.e. Candida neoformans ATCC 90112).

The bacterial pathogens were maintained on Mueller Hinton Agar medium while Candida neoformans was maintained on Potato Dextrose Agar at $4{ }^{\circ} \mathrm{C}$. Overnight nutrient broth subculture of the test organisms were done before use (Elbeshehy et al., 2015). 


\section{Agar well diffusion method}

The antimicrobial activity of three algal crude extracts derived from Padina boryana Thivy and Enteromorpha sp were tested by using agar diffusion technique. The Mueller Hinton Agar for bacterial and PDA for fungal strain were poured into Petri plates then inoculated with microbial inocula (containing $10^{5}-10^{6} \mathrm{CFU} / \mathrm{mL}$ ) that spread onto the agar surface of the plates using a sterile cotton swabs in order to get a uniform microbial growth on both control and test plates. Algal crude extracts were dissolved in dimethyl sulfoxide (DMSO) to a final concentration $1 \mathrm{mg} / \mathrm{mL}$, sterilized by filtration using sintered glass filter, and stored at $4^{\circ} \mathrm{C}$. $6 \mathrm{~mm}$ diameter wells were dug on the inoculated nutrient agar medium using sterilized cork borer and $50 \mu \mathrm{l}$ of each extract were transferred into the wells. In each plate one well loaded with DMSO was used as a negative control. Bacterial strains were incubated at $37{ }^{\circ} \mathrm{C}$ overnight while plates inoculated with $C$. neoformans were incubated at $28^{\circ} \mathrm{C}$ for $48 \mathrm{~h}$. After incubation, the diameter of inhibition zone of bacterial growth around the agar wells was calculated in $\mathrm{mm}$.

\section{Minimum inhibitory concentration (MIC)}

The standard micro-dilution method in 96-well plates from the Clinical Laboratory Standards Institute was carried out to evaluate the MIC. The effective algal extracts were selected and dissolved in water containing $4 \%$ DMSO and the initial extract concentration was $500 \mathrm{ug} / \mathrm{ml}$. $50 \mu \mathrm{L}$ of each extract was serially diluted two-fold with $\mathrm{MH}$ broth (Difco, MD, USA), ranging the concentrations between 500 to $7.8 \mu \mathrm{g} / \mathrm{ml}$. Each well was inoculated with $(50 \mu \mathrm{L})$ of four sensitive tested bacterial strains at $10^{6}-10^{7}(\mathrm{CFU} / \mathrm{ml})$. The plates were incubated overnight at $37^{\circ} \mathrm{C}$, and then the optical density at $600 \mathrm{~nm}$ was measured using a BioRad Microplate Reader Model-550 (Bio-Rad, USA). Wells without inoculum added were used as controls, and positive controls (tetracycline and ciprofloxacin) were added to the inoculated growth medium without the substances. The MIC was recorded as the lowest concentration of antimicrobials extract with no visible growth of bacteria (Elazzazy et al., 2015).

\section{Statistical analysis}

All data are presented as means $\pm \mathrm{SD}$; the mean values were calculated based on the data taken from at least three independent experiments conducted on separate days using freshly prepared reagents.

\section{RESULTS AND DISCUSSION}

\section{Total phenolic (TP) and total flavonoid (TF) contents of two marine algae}

Phenolic compounds in particular are considered as one of the most important classes of natural products. Phenolics act as antioxidants by inhibiting enzymes involved in radical generation and exhibited anticancer, antibacterial, anti-allergic, anti-diabetes, anti-aging, and anti-HIV activities, (Fresco et al., 2006 and Li, et al., 2011). Thus, the total phenolic and total flavonoid contents of three different solvent extracts (ethanol, acetone and hexane) of Padina boryana Thivy and Enteromorpha were evaluated and the results are presented in table (1). The total phenolic contents(21.81 \pm 0.11 and $15.22 \pm 0.13 \mathrm{mg} / \mathrm{g}$ gallic acid equivalent) were found to be higher in ethanol and acetone extracts of Padina boryana Thivy followed by $(15.31 \pm 0.02$ and $5.17 \pm 0.11 \mathrm{mg} / \mathrm{g}$ gallic acid equivalent) in ethanol and acetone extracts of Enteromorpha sp., respectively. The ethanol and acetone solvents presented the highest values of total flavonoid contents $(13.11 \pm 0.14$ and $12.09 \pm 0.02 \mathrm{mg} / \mathrm{g}$ quercetin equivalent) in Padina boryana Thivy and $(6.13 \pm 0.01$ and $4.91 \pm 0.08 \mathrm{mg} / \mathrm{g}$ quercetin equivalent) in Enteromorpha sp., respectively (Table 1).In the present results Padina boryana Thivy showed TP and TF contents higher than Enteromorpha sp., and this difference perhaps could be attributed to genetic factors.

It was realized that within both algae species differences in TP and TF existed with the use of different solvents. This could be attributed to the polarity of the solvents (Hemalatha et al., 2011). Ethanol was considered to be the best solvent for extraction of TP and TF. Flavonoids are widely group of natural compounds and also the most important natural phenolics. In most algae, phenols are important antioxidants because of their ability to scavenge free radicals such as singlet oxygen, superoxide and hydroxyl radicals (Shanab et al., 2011).Results also show that, among all the solvent; ethanol and acetone were better solvents for effective extraction of phenolic compounds as compared to other solvent like hexane. This could be attributed to the polarity of the solvents (Hemalatha et al., 2011).It is very important to point out that; there is a positive relationship between antimicrobial activity potential and amount of phenolic compounds of the crude extracts (Mohamed et al., 2015).

\section{Antimicrobial activity:}

\section{Padina boryana Thivy and Enteromorpha}

Seaweeds such as Padina boryana Thivy and Enteromorpha $s p$ are broadly screened to isolate drugs or bioactive substances all over the world (Rao, 1991), they are able to produce a great variety of secondary metabolites characterized by a broad spectrum of antimicrobial activities (Cox et al., 2010). Accordingly, the present study was focused to screen ethanol, acetone and hexane extracts of Padina boryana Thivy and Enteromorpha $s p$ for the potential of antimicrobial activity on thirteen human pathogen aspresented in Figures 2 and 3 .Among the two marine algae screened Padina boryana Thivy was observed to be active than Enteromorpha sp. Three solvents tested, acetone exhibited more inhibitory effect followed by ethanol then hexane. For instance, the acetone extract of Padina boryana Thivy had strong antibacterial inhibition against gram negative bacteria Neisseria gonorrhoeae and Moraxella catarrhalis (22 and $21 \mathrm{~mm}$, respectively) followed by gram positive Methicillin-resistant Staphylococcus aureus $(20 \mathrm{~mm})$. The ethanol extracts of Padina boryana Thivy and Enteromorpha sp showed a broad spectrum of antimicrobial activity against Gram (+) and Gram (-) bacteria in addition to Candida. 


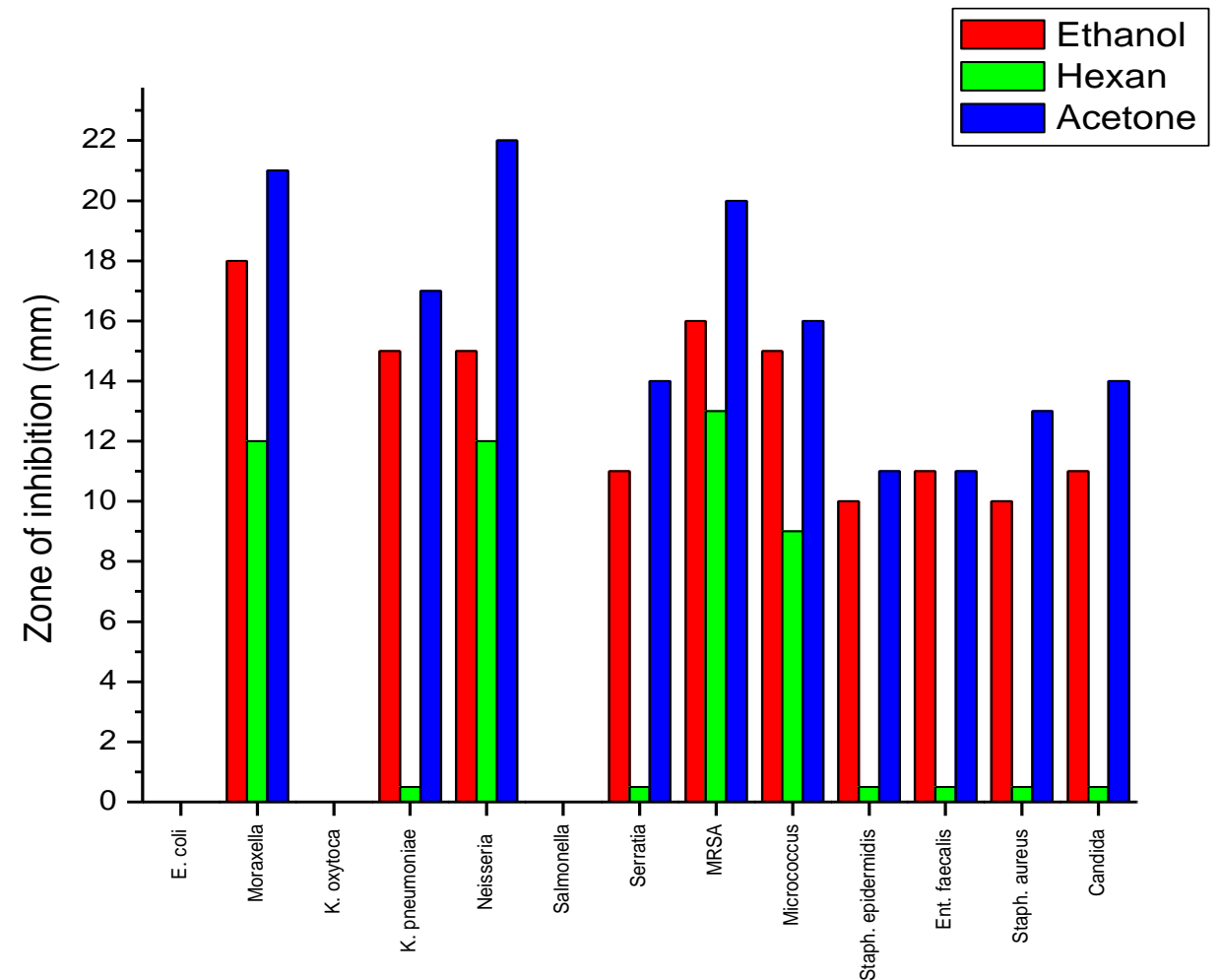

Fig. 2: Antimicrobial activity of Padina boryana Thivy against human pathogen. expressed by the inhibition zone (mm).

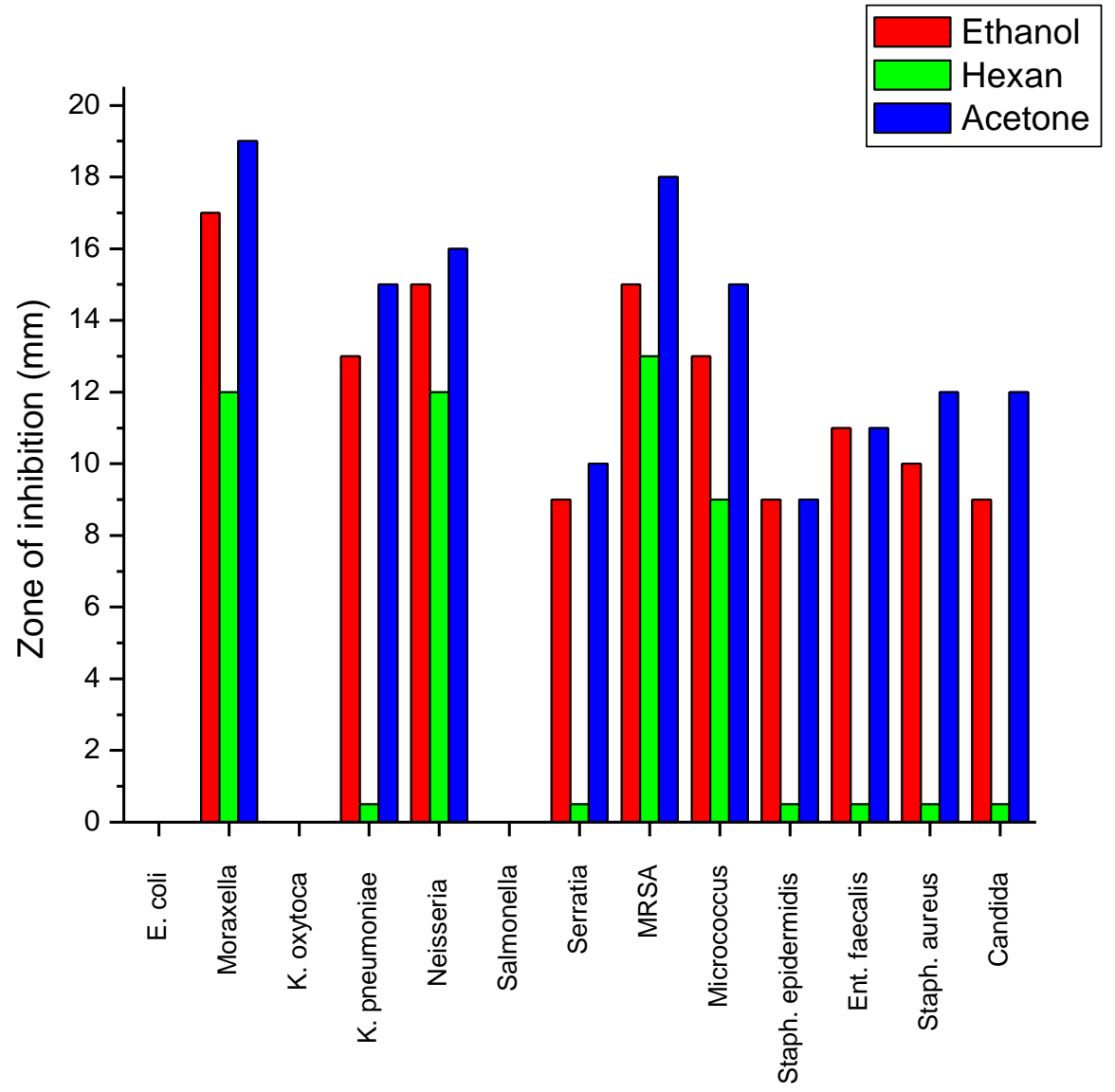

Fig. 3: Antimicrobial activity of Enteromorpha sp against human pathogen expressed by the inhibition zone (mm). 
However, hexane extracts of the two algal strains were only effective against MRSA, M. catarrhalis, N. gonorrhoeae and M. luteus among the bacteria tested. All the three solvent extracts of the two algae were not displayed any activity against three bacterial strains Salmonella, E. coli and Kleb. oxytoca.

The solvent system used for the extraction played a major role in displaying the anti-bacterial activity. In the present study, among the different solvent extract, acetone and ethanol extract of Padina boryana Thivy and Enteromorpha sp displayed highest inhibitory activity against the test pathogens as compared to hexane. This result are parallel to the highest content of TP and TF in acetone and ethanol extract (Table 1), thus the antimicrobial activity of Padina boryana Thivy and Enteromorpha sp might be attributed to their phenolic and flavonoid content. In this concern, a positive relationship between antimicrobial activity potential and amount of phenolic compounds of the crude extracts was reported (Mohamed et al., 2015).

Table 1: Total phenolic and flavonoid contents of Padina boryana Thivy and Enteromorpha in different solvent extracts.

\begin{tabular}{lccc}
\hline \multicolumn{1}{c}{ Algal species } & \multicolumn{3}{c}{ Solvents extract } \\
\hline & Ethanol & Acetone & Hexane \\
\hline \multicolumn{4}{c}{ Total phenolic $(\mathbf{m g} / \mathbf{g}$ d.wt) } \\
\hline Padina boryana Thivy & $21.81 \pm 0.11$ & $15.22 \pm 0.13$ & $9.04 \pm 0.02$ \\
Enteromorpha & $15.31 \pm 0.02$ & $5.17 \pm 0.11$ & $4.31 \pm 0.05$ \\
\hline \multicolumn{4}{c}{ Total flavonoids (mg/g d.wt) } \\
\hline Padina boryana Thivy & $13.11 \pm 0.14$ & $12.09 \pm 0.02$ & $5.15 \pm 0.07$ \\
Enteromorpha & $6.13 \pm 0.01$ & $4.91 \pm 0.08$ & $3.11 \pm 0.23$ \\
\hline
\end{tabular}

Ethanol was found to be the best solvent for extracting the active principles in almost all species of seaweeds (Rebecca et al., 2013). Some studies concerning the effectiveness of extraction methods highlight that methanol extraction yields higher antimicrobial activity than n-hexane and ethyl acetate (Tuney et $a l ., 2006)$. It is clear that using organic solvents always provides a higher efficiency in extracting compounds for antimicrobial activities compared to water-based methods (Lima-Filho et al., 2002). The minimum inhibitory concentration of Padina boryana Thivy and Enteromorpha sp were carried out using the acetone and ethanol extract, which showed the maximum activity, against most sensitive bacterial strains, as presented in Table 2.As the MIC value decreased the antibacterial increase. The acetone extract of Padina boryana Thivy and Enteromorpha sp showed highest activity against $M$. catarrhalis, MRSA and N. gonorrhoeae with the lowest MIC values $(31,62$ and $125 \mu \mathrm{g} / \mathrm{ml})$, respectively. Whereas, the ethanol extract of Padina boryana Thivy showed the lowest activity against MRSA and N. gonorrhoeae with MIC value (125 $\mu \mathrm{g} / \mathrm{ml})$, while, the ethanol extract of Enteromorpha $s p$ exhibited lowest activity against $M$. catarrhalis, with MIC value $(125 \mu \mathrm{g} / \mathrm{ml})$. Sahgal et al., (2011) attributed the differences of the MIC value could be due to the morphological structure of the bacterial cells and their composition in the cells. The reduction in growth possibly occurred due to interference by active compounds in the extract (Beatrice et al., 2010). Similarly, Lim et al., (2011) and Darah et al., (2013) reported that the higher concentration of the extract was needed to kill the microorganism cells than to inhibit the growth of these cells on time-kill profile study.

Table 2: MIC $(\mu \mathrm{g} / \mathrm{ml})$ values of Padina boryana Thivy and Enteromorpha $s p$ Against Human Pathogens in M-H Broth.

\begin{tabular}{lcccc}
\hline \multirow{2}{*}{ Pathogenic organisms } & \multicolumn{2}{c}{$\begin{array}{c}\text { Padina boryana } \\
\text { Thivy MIC (ug/ml) }\end{array}$} & \multicolumn{2}{c}{$\begin{array}{c}\text { Enteromorpha sp } \\
\text { MIC (ug/ml) }\end{array}$} \\
\cline { 2 - 5 } & Ethanol & Acetone & Ethanol & Acetone \\
\hline N. gonorrhoeae & $125 \pm 2$ & $125 \pm 4$ & $250 \pm 1$ & $125 \pm 0$ \\
MRSA & $125 \pm 1$ & $62 \pm 3$ & $500 \pm 2$ & $\mathbf{6 2} \pm \mathbf{2}$ \\
M. catarrhalis & $250 \pm 0$ & $31 \pm 1$ & $125 \pm 3$ & $\mathbf{3 1} \pm \mathbf{4}$ \\
Serratia sp & $500 \pm 0$ & $250 \pm 0$ & $500 \pm 3$ & $250 \pm 3$ \\
C.neoformans & $500 \pm 0$ & $500 \pm 0$ & $250 \pm 0$ & $500 \pm 5$ \\
Klebsiella pneumoniae & $250 \pm 0$ & $250 \pm 0$ & $500 \pm 0$ & $500 \pm 0$ \\
Micrococcus luteus & $250 \pm 0$ & $250 \pm 0$ & $500 \pm 0$ & $500 \pm 0$ \\
\hline
\end{tabular}

\section{CONCLUSION}

Seaweeds contained high levels of hydrophilic components, such as polyphenols which were easily extracted by polar solvents. Overall results of this study showed that ethanol and acetone solvents were effective for polyphenols extraction from Padina boryana Thivy and Enteromorpha sp. As well as the two extracts exhibited strong antimicrobial activity against the tested microorganisms. MRSA, M. catarrhalis and N. gonorrhoeae were the most sensitive bacterial strains for the acetone extract of Padina boryana Thivy and Enteromorpha $s p$. This suggests that algalpolyphenols including flavonoids may be the principal constituents responsible for the antimicrobial properties of extracts from this species. These findings suggested that there may be a potential to utilize such seaweed extracts in food products to act as antimicrobial which would have promising applications in enhancing the food safety.

\section{Financial support and sponsorship: Nil.}

Conflicts of interest: There are no conflicts of interest.

\section{REFERENCES}

Abd El-Aty, Azza M. ; Mohamed A. Amal, Samhan Farag A. In vitro antioxidant and antibacterial activities of two fresh water Cyanobacterial species, Oscillatoria agardhii and Anabaena sphaerica. Journal of Applied Pharmaceutical Science, 2014; 4 (07), 069-075.

Ayyad, S.N., Abdel-Halim, O.B., Shier, W.T., and Hoye, T.R. Cytotoxic Hydroazulene Diterpenes from the Brown Alga Cystoseira myrica. Z. Naturforsch, 2003; 58c, 33-38.

Beatrice O.T.I., Darah I., Supayang P.V. Antimicrobial activity of crude ethanolic extract from Eleutherine Americana J Food Agric Environ, 2010; 8:1233-1236.

Burtin, P. Nutritional value of seaweeds. Electronic Journal of Environmental, Agricultural and Food Chemistry, 2003; 2(4), 498-503.

Cantillo-Ciau Z, Moo-Puc R, Quijano L, Freile-Pelegrin Y. The tropical brown alga lobophora variegata: A source of antiprotozoal compounds. Mar. Drugs, 2010; 8: 1292-1304.

Chandini, S.K., GANESAN, P. and BHASKAR, N. In vitro antioxidant activities of three selected brown seaweeds of India. Food Chem, 2008; 107, 707-713.

Cox S, Abu-Ghannam N, Gupta S. An assessment of the antioxidant and antimicrobial activity of six species of edible Irish seaweeds. Int Food Res J, 2010; 17: 205-220. 
Darah I., Jain K., Lim S.H., Wendy R. Efficacy of pyroligneous acid from Rhizophora apiculata on pathogenic Candida albicans. J Appl Pharm Sci, 2013; 3: 7-13.

Elazzazy AM, Abdelmoneim TS, Almaghrabi OA. Isolation and characterization of biosurfactant production under extreme environmental conditions by alkali-halo-thermophilic bacteria from Saudi Arabia.Saudi J Biol Sci, 2015; 22(4):466-75.

Elbeshehy EKF, Elazzazy AM, Aggelis G. Silver nanoparticles synthesis mediated by new isolates of Bacillus spp., nanoparticle characterization and their activity against Bean Yellow Mosaic Virus and human pathogens. Frontiers in Microbiology, 2015; 6: 453. doi:10.3389/fmicb.2015.00453.

Flodin C, Whitfield FB. Brominated anisoles and cresols in the red alga Polysiphoniasphaerocarpa. Phytochemistry, 2000; 53(1): 77-80.

Fresco, P., Borges, F., Diniz, C., Marques, M.P.M. Newinsights on the anticancer properties of dietary polyphenols. Med.Res. Rev, 2006; 26: 747-766.

Gupta S, Abu-Ghannam N. Bioactive potential and possible health effects of edible brown seaweeds. Trends Food Sci. Techn, 2011; 22: $315-326$

Hemalatha ,A., K. Girija, C. Parthiban, C. Saranya and P. Anantharaman. Antioxidant properties and total phenolic content of a marine diatom, Navicula clavata and green microalgae, Chlorella marina and Dunaliella salina. Advances in Applied Science Research, 2013, 4(5): 151-157.

Jin DQ, Lim CS, Sung JY, Choi HG, Ha I, Han JS. Ulva conglobata a marine algae, has neuroprotective and anti-inflammatory effects in murine hippocampal and microglial cells. Neuroscience letters. 2006; 402: 154-158

Li, Y.X.; Wijesekara, I.; Li, Y.; Kim, S.K. Phlorotannins as bioactive agents from brown algae. Process Biochem, 2011; 46: 2219 2224.

Lim S.H., Darah I., Jain K., Suraya S. Gallic acid: an anticandidal compound in hydrolysable tannin extracted from the barks of Rhizophora apiculata Blume . J Appl Pharm Sci, 2011; 01 (06): 75-79.

Lima-Filho JV, Carvalho AF, Freitas SM. Antibacterial activity of extracts of six macroalgae from the Northeastern Brazilian Coast Brazilian J. Microbiol, 2002; 33: 311-313.

Lincolon, R.A., Strupinski, K., and Walker, J.M. Bioactive compounds from algae. Life Chem. Rep, 1991; 8: 97-183.

MacArtain P., Gill C.I.R, Brooks M., Campbell R., Rowland I.R. Nutritional Value of Edible Seaweeds. Nutrition Reviews, 2007; 65: 535-543.

Mohamed Amal A., Sami I. Ali, Osama M. Darwesh, Salwa M. El-Hallouty, Manal Y. Sameeh. Chemical compositions, potential cytotoxic and antimicrobial activities of Nitraria retusa methanolic extract sub-fractions. International journal of toxicology and pharmacological research. 2015; 7(4).

Nor Afifah S, Sarah I, Shade FS, Mohd Jain NM, Nurul AZ. Antimicrobial activity of various extracts of a tropical Chlorophyta macroalgae, Halimeda discoidea. J. Appl. Sci., 2010; 10: 3007-3013.
Nair R, Chabhadiya R, Chanda S. Marine algae: screening for a potent antibacterial agent. J Herb Pharmacother, 2007; 7 (1):73-86.

O’Sullivan L, Murphy B, McLoughlin P, Duggan P, Lawlor PG, Hughes $\mathrm{H}$, et al., Prebiotics from marine macroalgae for human and animal health applications. Mar Drugs, 2010; 8 (7):2038-64.

Paul G, Yusuf S, Sharma S. Unmasking of the Brugada syndrome phenotype during the acute phase of amiodarone infusion Circulation, 2006; 114(11):489-491.

Rao P. S. P. Biological investigation of Indian marine algae and screening of some green, red and brown seaweeds for their antimicrobial activity. Seaweed Res Utiln, 1991; 14(1): 37-43.

Rebecca J. L, Dhanalakshmi V, Sharmila S, and Merina P. Das. In vitro antimicrobial activity of Gracilaria SP and Enteromorpha SP. Research Journal of Pharmaceutical, Biological and Chemical Sciences (RJPBCS), 2013 (4) 693-697.

Sahgal G., Ramanathan S., Sasidharan S., Mordi M.N., Ismail S., Mansor S.M. In vitro and in vivo anticandidal activity of Swietenia mahogany methanolic seed extract Trop Biomed, 2011; 28 (1): 132-137

Shanab SMM, Shalaby EA, El-Fayoum EA. Enteromorpha compressa Exhibits Potent Antioxidant Activity. J Biomed Biotechnol 2011.

Slinkard K, Singleton VL. Total phenol analyses: automation and comparison with manual methods. Am. J. Enol. Vitic. 1977; 28: 4955 .

TuneyI, Çadirci BH, Unal D, Sukatar A. Antimicrobial activities of the extracts of marine algae from the coast of Urla (Azmir, Turkey). Turk J Biol, 2006; 30: 171-5.

Zaragoza MC, Lopez D, Saiz MP, Poquet M, Perez J. et al., Toxicity and antioxidant activity in vitro and in vivo of two Fucus vesiculosus extracts. J.Agric. Food Chem, 2008; 56: 7773-7780.

Zhishen, J., Mengcheng, T., Jianming, W. The determination of flavonoid contents in mulberry and their scavenging effects on superoxide radicals. Food Chem, 1999; 64: 555-559.

\section{How to cite this article:}

Sameeh MY, Mohamed AA, Elazzazy AM. Polyphenolic contents and antimicrobial activity of different extracts of Padina boryana Thivy and Enteromorpha sp marine algae. J App Pharm Sci, 2016; 6 (09): 087-092. 